\title{
Misconceptions among Middle School Students Regarding the Conservation of Mass during Combustion
}

\author{
Ahmad Basheer ${ }^{1 *}$, Naji Kortam ${ }^{1}$, Nisreen Zahran ${ }^{1}$, Avi Hofestein ${ }^{2}$, Muhamad Hugerat ${ }^{1}$ \\ ${ }^{1}$ The Academic Arab College for Education in Israel, Haifa, ISRAEL \\ ${ }^{2}$ The Weizmann Institute of Science, ISRAEL
}

Received 29 September 2017 • Revised 17 April 2018 • Accepted 26 April 2018

\begin{abstract}
This study focuses on the misconceptions of eighth-grade students in the Arab sector compared to the Jewish sector regarding the conservation of mass during combustion in a closed system and in an open system before the subject is taught, and to what extent the misconceptions change after it is taught. Students $(\mathrm{N}=195)$ from six heterogeneous classes were asked to fill in a ten-question questionnaire twice: once before the subject was taught and again afterwards. The findings indicated that students' understanding improved more with respect to closed systems compared with open systems; before the subject had been taught the situation was very similar for both cases. The students' explanations were based on visual arguments and showed that there was confusion concerning the effect of chemical, physical, and state of matter changes on the conservation of mass during combustion. Regarding the comparison between the conceptions of eighth-grade students in the Arab and Jewish $(\mathrm{N}=105)$ sectors, students in the Arab sector had better achievements in closed systems, whereas Jewish students gave more correct answers to questions in open systems. The study's findings can help middle-school students and their teachers understand that physical and chemical changes do not affect mass in a closed system, and that students should learn to distinguish between conservation of mass in open and in closed systems.
\end{abstract}

Keywords: chemical changes, combustion, mass conservation, misconceptions, physical changes

\section{INTRODUCTION}

Chemical reactions are one of the six basic concepts in chemistry and combustion is one of the most important oxidation-reduction reactions in general chemistry (Gillespie, 1997). Conservation of mass during combustion is a sub-topic in the study of chemical reactions, which is learned in middle school. The law of the conservation of mass is basic for our understanding of the world, and for understanding that energy is neither created nor disappears (Ochsendorf \& Pyke, 2004, p.13). If one mixes a large quantity of different materials inside a closed system, the total mass is the same before and after the chemical reaction, irrespective of the amount of matter (even if the original materials are combined or separated). Middle-school students must therefore learn that physical and chemical changes in a closed system do not affect the amount of mass (Ochsendorf \& Pyke, 2004). Piaget and Inhelder (1974) stressed that it is quite difficult for students to understand the concept of the conservation of mass in chemical reactions; in order to clarify the issue for them it is necessary to explain about volume, weight, and sometimes the density of matter. Stavy (1990a, 1990b, 1990c) maintains that if one uses colored gas, students find it easier to understand changes in matter than if the gas is colorless, because something invisible is perceived as mysterious. Ochsendorf and Pyke (2004) claim that in order to understand the conservation of mass, one must first understand the molecular structure of matter, that is, that matter consists of particles that undergo changes but they do not disappear.

(C) 2018 by the authors; licensee Modestum Ltd., UK. This article is an open access article distributed under the terms and conditions of the Creative Commons Attribution License (http://creativecommons.org/licenses/by/4.0/).

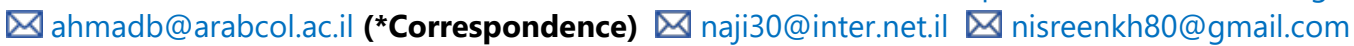




\section{Contribution of this paper to the literature}

- This study concentrates on misconceptions conservation of mass during combustion in a closed system and in an open system.

- Comparing misconceptions among eighth graders regarding the preservation of mass in combustion process between Arab and Jewish sectors in Israel who studying the same curriculum.

- Students' understanding improved more with respect to closed systems than with respect to open systems. Nevertheless, students in the Arab sector had better achievements in closed systems, whereas Jewish students had better achievements in open systems.

Misconceptions are generally defined as concepts structured inadequately or incorrectly by students, apart from concepts scientifically accepted as true, and that were acquired by students by the end of the educational process (Nakhleh, 1992). The main characteristics of misconceptions are that students construct alternative definitions for the concepts studied; many of them believe in them as scientific fact, and it is very hard to change such incorrect beliefs (Fisher, 1985). Moreover, misconceptions result from the student's attempts to understand their previous experiences resulting from their interaction with their environment and they must be taken into account in educational practice to design appropriate instructional strategies that will impulse their evolution into more scientific-academic concepts (Cañada et al., 2017). Barker and Millar (1999) found that students have difficulty understanding the conservation of mass and chemical reactions inside a closed system. For example, a piece of phosphorous was added to a bottle, which was then closed. The total mass was $400 \mathrm{~g}$. The bottle was then exposed to sunshine and after a while, white smoke arose and was then dissolved in water. The students were then asked if the mass increased, decreased, or remained the same; thirty-seven percent replied that the mass had changed. Other studies also found misconceptions about the conservation of mass in chemical reactions (Ayas \& Ozmen, 2003; Driver, Guesne, \& Tiberghien, 1985; Nussbaum \& Yehieli, 1995; Ochsendorf \& Pyke, 2004) and in processes involving creating solutions (Andersson, 1984; Ochsendorf \& Pyke, 2004). Hesse (2006) found that high-school students have difficulty in distinguishing physical from chemical changes and in explaining invisible processes (such as the release of gases). Students use made-up terms to explain various chemical reactions (Driver et al., 1985). When perfume is poured on a surface (an open system), it eventually evaporates (a physical change). Students explained that when matter becomes a gas it disappears, as do its atoms (Ochsendorf \& Pyke, 2004). Eilks, Moellering and Valandies (2007) showed that students think that the material created in a chemical reaction consists of a mixture of materials. It is easier for them to explain phenomena at the macroscopic than at the microscopic level; they think that particles can be transformed into different ones in the same material.

Combustion is a chemical reaction involving oxygen and is accompanied by the emission of heat. Studies from around the world have shown that many middle- and high-school students cannot provide the correct chemical explanation for combustion and give erroneous answers, based on a lack of understanding the law of the conservation of mass (Boujaoude, 1991).

In a study in a middle school $(\mathrm{N}=20)$, students were asked to predict the change in mass when a candle burned in a closed system. Twelve students said there would be no change and eight said that the mass of the system would decrease (Boujaoue, 1991). In another experiment, students were asked about the mass of wood after it was burned. Some of them argued that the mass would be smaller, because the combustion products look smaller. On the other hand, when wood was burned to ash (in an open system) and students were asked why the mass decreased, some said that the number of atoms in the combustion products was smaller, and that therefore, the mass was less (Ochsendorf \& Pyke, 2004). Interviews with the students revealed that they still held on to misconceptions after having been exposed to a number of experiments and examples. They used everyday words to describe chemical and physical changes, without giving a thought to their meaning as scientific terms (Boujaoue, 1991).

In a paper by Watson, Prieto, and Dillon (1995), the objective was to discover conceptions and misconceptions on combustion among students in England and Spain. Some of the students explained the chemical reactions without referring to the interaction between oxygen and the flammable material; their answers were based on the concept of "melting" - oxygen was not necessary for combustion and was metamorphosed by the fire. In Spain the method by which the subject was taught was that the teacher performed the experiment and explained it while the students listened and created knowledge, whereas in England it was the students who performed the experiment while the teacher explained the result. Despite the different teaching methods in the two countries, the study showed that students in both countries exhibited misconceptions about combustion, as manifested by erroneous explanations for what had happened. However, in an earlier study (Prieto, Watson, \& Dillon, 1992; Watson \& Prieto, 1994), it was argued that the different methods used in these two countries were significant and affected students' understanding of the topic.

Ayas and Ozmen (2003) studied how students aged fifteen and sixteen comprehended the law of the conservation of mass in a closed system. They found a number of misconceptions among the students, some of 
whom stated that when a solid is precipitated in a chemical reaction the total mass increases, because the solid is heavier than the liquid, whereas when combustion is incomplete in a closed system, the total mass of reagents and products always decreases. However, Driver et al. (1985) found that almost one-half of the students replied that the mass of an iron coil will decrease after combustion, but only one-third of them replied that a rusty nail has more mass. A study of eighty-seven students (forty-one in high school and forty-six in middle school) in Turkey revealed misconceptions about the conservation of matter, its chemical composition at various stages, and the behavior of molecules during a chemical process at the microscopic level (Leigh \& Mehmet, 2012). Another study on combustion reactions indicated that students aged eight to thirteen do not give a correct explanation of combustion, the role of oxygen, and dissociation (Gabel, Makinster, Monaghan, \& Stockton, 2007).

Dayan (2005) focused on conceptions of the conservation of mass during combustion among students in the Jewish sector. She found that twice as many students gave correct answers regarding the conservation of mass during combustion in both open and closed systems after the subject had been taught than before.

The law of the conservation of mass is not easy for students to understand; it requires an understanding of chemical reactions (Ayas \& Ozmen, 2003). It is a fundamental topic in the chemistry syllabus. Students often retain misconceptions about it even after the subject has been taught. For example, in the case of the combustion of a gas, students find it hard to comprehend that when it takes place in an open system, mass is added. Students' answers are intuitive (Melamed, 2000) and/or naïve (Pundak, Rosner, \& Maharshak, 2005), and reflect a misrepresentation of scientific conceptions. One possible reason for this is that students may find it difficult to distinguish the macroscopic from the microscopic world, and therefore, do not understand chemical reactions and the conservation of mass (Sanz, 2006).

Because students in middle school do not gain a proper understanding of the chemical process mentioned in the syllabus, involving conservation or the change in mass during combustion, they find it difficult to answer questions on this subject in the matriculation examination, owing to their not having internalized learning strategies based on scientific thinking.

Children should be introduced at an early stage of education to learning strategies in various domains of knowledge, through research, laboratory experimentation, and text analysis. This is important because such students will, at a more advanced stage, be able to more successfully engage in scientific thinking in their answers (Mendelowitz, 1996).

In Israel, various studies have been carried out in the teaching of sciences that examined cultural-sector differences between Arabs and Jews (Birenbaum, Nasser, \& Tatsuoka, 2007; Dkeidek, Mamlok-Naaman, \& Hofstein, 2011; Markic et al., 2016; Tamir \& Caridin, 1985). Most of the findings in these studies indicated many differences between the two sectors.

Tamir and Caridin, (1993) showed that the achievement of Arab students are lower when the task requires abstract thinking. Arab culture is known for its tendency to promote learning by reciting and memorizing facts rather than Jewish culture. A study by Abdu (1999), which examined the concept of "living creature" among a large Arab population of young students (grades 5, 6 and 10) and adults (including science teachers and non-science teachers) found that $12 \%$ of the teachers (including Science teachers) attributed life traits to objects: Cloud and fire, a slightly lower percentage of those objects as living among their students $(17 \%)$. He found that the cultural component has a clear effect in the classification of inanimate objects as living or still. The reasons given during personal interviews attributed the incorrect classifications of these inanimate to religious-cultural influences, such as the "holy fire" which appears in the church's ceremony. The Quran also states that during a thunderstorm, thunder and lightning show that the clouds are "praying".

Birenbaum et al. (2007) in a study that examined the gender and ethnicity effect on mathematics achievements in an international test, in a representative sample of Arabs and Jews from the $8^{\text {th }}$ grade in Israel, found a large gap in the achievement for the benefit of Jewish students. The researchers attributed that to cultural differences between Arabs and Jews in Israeli society, as well as differences in learning environments.

In addition, a comparative study by Dkeidek et al., (2012) to examine the socio-sectoral background of students on the investigation of the chemistry laboratory in secondary schools in both the Arab and Jewish sectors, there were differences between Arab students and Jewish students (who study chemistry with inquiry approach) regarding their perception of the learning environment: Arab students had a more positive attitude than Jewish students regarding practical work in the laboratory. The ability of questions asking as a result of reading a scientific paper, and/or following a new research experiment, was higher among Jewish in terms of number questions and their cognitive level. The researcher explains that to differences in culture, tradition, norms, social structure and lifestyle. 


\section{Objectives and Research Questions}

The main goal of this study was to reveal the misconceptions among middle-school students in the Arab sector in Israel regarding the subject of the conservation of mass during combustion in closed systems, and the changes in mass in open systems, before and after the subject is taught. Another goal was to compare the findings in the Arab sector to those in the Jewish sector concerning the role of oxygen atoms in combustion, understanding the law of the conservation of mass, and changes in mass in various situations.

For that purpose, we formulated the following two research questions:

1. What are the conceptions of eighth grade students in the Arab sector regarding the conservation of mass during combustion in a closed versus an open system before the subject is taught, and how do these conceptions change after it is taught?

2. How do the conceptions of eighth grade students in the Arab sector differ from those of their peers in the Jewish sector regarding the conservation of mass during combustion in a closed versus an open system before the subject is taught, and how do they change after it is taught?

\section{METHODS AND RESEARCH SAMPLE}

Israel is a multicultural state with the Jewish and the Arab communities as being the biggest sectors. The schooling system is the same for the Jewish and Arab sectors. Schooling is compulsory until the age of 16 . In upper secondary education different types of schools with different academic and vocational orientations are available. However, Israel has a centralized educational system. The syllabi and curricula are regulated by the Ministry of Education. Only the language of teaching and cultural issues in the curriculum are specific for the respective sector. From the 1990s on words, the Ministry of Education is in charge for the long-term and dynamic development of science curricula and its implementation.

The sample consisted of students in six heterogeneous eighth grade classes $(\mathrm{N}=195)$ from a two secondary middle school in the Arab sector with similar socio-economic backgrounds. The students were selected using a convenience sample. The general criteria by which the students were chosen were as follows: a willingness to cooperate throughout the entire study, concentration and perseverance, passable verbal expression skills, and varied learning ability in class via experiments and discussions. The study conducted in the Jewish sector took place in a six-year comprehensive school. The study population consisted of three heterogeneous eighth grade classes $(\mathrm{N}=105)$, with students of varying cognitive abilities and from similar socio-economic backgrounds. In seventh grade the students from both groups had learned about the characteristics of matter, and its molecular structure, as well as about chemical and physical processes, including the conservation of mass and energy.

In this study, a quasi-experimental research method, was used. A questionnaire, consisting of ten open and closed questions focusing on the conservation of mass during combustion, was administered to the students. The questions were taken from three different sources: Questions 1-4 and 6-9 from Dayan (2005), question 5 from Ayas and Ozmen (2003), and question 10 from the Israel Ministry of Education's approved syllabus for middle school (Levy Nahum, Moyal, Somekh, \& Koshinsky, 2010). The questions required students to provide the correct answer and some also requested an explanation. The questionnaire consisted of two parts: The first part (questions 1-5) consisted of questions about the conservation of mass during combustion in a closed system, whereas the second part (questions 6-10) consisted of questions about the conservation of mass during combustion in an open system. The questionnaire was adapted mainly from that of Dayan (2005) and was modified for the present study using a pilot study consisting of 32 eighth grade pupils.

Two types of validation processes were conducted: The questionnaire underwent of several types: Content validity. The content validation was conducted by four experts from science education: one doctor of chemistry and two doctors of science education and a veteran teacher of chemistry in junior high schools. This group received the questionnaire for review and its members expressed their opinion on the scope, content and form of the questionnaire. The comments they made were taken into consideration and the questionnaire was amended accordingly. Criterion validity. The questions in the questionnaire were written in accordance with the formal curriculum designed by the Ministry of Education for the relevant $8^{\text {th }}$ grade. The achievement test was content validated by and checked by a group of 5 experience Arab teachers who teach the topics of the test. The a-Cronbach reliability coefficient (for the Hebrew version) of the test questionnaire was 0.83 Dayan (2005).

Misconceptions were tested by means of the ten questions in the questionnaire. For each question the number of correct and incorrect judgments was checked, before and after the subject had been taught. The responses were divided according to the explanations given by the students and the percentage of correct and incorrect explanations, before and after the subject had been taught, was calculated. The distribution of correct answers and explanations was calculated according to the percentage of correct answers in the questionnaire's two parts (closed and open systems), before and after the subject had been taught. Finally, the data elicited from the questions about 
conservation of mass during combustion in a closed (questions 1-4) and in an open system (questions 6-9) for the Arab sector were compared with those for the Jewish sector (Dayan, 2005). A t-test was made for dependent samples where a comparison was needed.

\section{Research Procedure}

The questionnaire was distributed twice in science class: before the subject was taught and again after the subject had been taught over the course of six lessons, including experiments and class discussions, as follows:

Lesson 1: The idea of macroscopic and microscopic levels in chemistry.

Lesson 2: The difference between physical and chemical change.

Lesson 3: Combustion as a chemical process, and the law of the conservation of mass.

Lessons 4-6: Measurement of materials in different states, before and after combustion, in an open and a closed system, using experiments and classroom discussions.

During the entire teaching process, every lesson ended with a summary based on a classroom discussion concerning students' preexisting conceptions and the conceptions they had acquired during the lesson. In the last stage the questionnaire was distributed again to see whether students' conceptions had changed following the lessons. Students were given forty-five minutes to fill it in.

\section{RESULTS}

\section{Findings for the First Research Question}

First, we will present the main misconceptions from both the open and closed systems.

Table 1. Eighth grade students' misconceptions about the conservation of mass during combustion in a closed and an open system

\begin{tabular}{|c|c|}
\hline Closed system & Open system \\
\hline $\begin{array}{l}\text { - Combustion causes a decrease in mass, because some of the } \\
\text { material evaporates. }\end{array}$ & $\begin{array}{l}\text {-When a solid piece of matter (a strip of magnesium) burns, } \\
\text { the resulting mass will be less than the original solid, because } \\
\text { it disintegrated and became lighter. }\end{array}$ \\
\hline $\begin{array}{l}\text { - The system's mass will increase because oxygen atoms from } \\
\text { the air combine with the matter during combustion. }\end{array}$ & $\begin{array}{l}\text { When a magnesium strip burns, the resulting mass will be } \\
\text { less than that of the solid; light gasses are formed. }\end{array}$ \\
\hline $\begin{array}{l}\text { - The mass will decrease because some of the oxygen atoms in } \\
\text { the air disappeared during combustion. }\end{array}$ & $\begin{array}{l}\text {-When a solid (iron) burns, the resulting mass will be smaller, } \\
\text { because the volume decreased. }\end{array}$ \\
\hline $\begin{array}{l}\text { - The mass is not equal because some of the oxygen atoms in } \\
\text { the air disappeared. }\end{array}$ & $\begin{array}{l}\text { - After a candle is lit, the system's mass grows because oxygen } \\
\text { atoms have been added. }\end{array}$ \\
\hline $\begin{array}{l}\text { - In a closed system there is no oxygen; therefore, combustion } \\
\text { will not take place and the mass will not change. }\end{array}$ & $\begin{array}{l}\text { - After a candle is lit, the system's mass grows because the } \\
\text { light's mass is added. }\end{array}$ \\
\hline $\begin{array}{l}\text { - The ash produced in combustion is heavier than the material } \\
\text { that was burned; therefore, the mass increases. }\end{array}$ & $\begin{array}{l}\text { - When a piece of paper is burned the mass of the product is } \\
\text { less because the ash that is formed consists of small pieces } \\
\text { that fall apart. }\end{array}$ \\
\hline
\end{tabular}

As shown in Table 2, answers to questions 1-10, regarding eighth grade students' conceptions of the conservation of mass during combustion in a closed and open system. 
Table 2. Summary of students' responses in Arab sector to questions 1-5, on the conservation of mass during combustion in closed and open systems, before and after the subject is taught (N-195)

\begin{tabular}{|c|c|c|c|c|c|c|c|c|c|c|}
\hline \multirow{2}{*}{$\begin{array}{c}\text { Question no. } \\
\text { Judgment }\end{array}$} & \multicolumn{2}{|c|}{1} & \multicolumn{2}{|c|}{2} & \multicolumn{2}{|c|}{3} & \multicolumn{2}{|c|}{4} & \multicolumn{2}{|c|}{5} \\
\hline & $\begin{array}{c}\text { Before } \\
\text { subject } \\
\text { taught }\end{array}$ & $\begin{array}{c}\text { After } \\
\text { subject } \\
\text { taught }\end{array}$ & $\begin{array}{l}\text { Before } \\
\text { subject } \\
\text { taught }\end{array}$ & $\begin{array}{c}\text { After } \\
\text { subject } \\
\text { taught }\end{array}$ & $\begin{array}{l}\text { Before } \\
\text { subject } \\
\text { taught }\end{array}$ & $\begin{array}{c}\text { After } \\
\text { subject } \\
\text { taught }\end{array}$ & $\begin{array}{l}\text { Before } \\
\text { subject } \\
\text { taught }\end{array}$ & $\begin{array}{c}\text { After } \\
\text { subject } \\
\text { taught }\end{array}$ & $\begin{array}{l}\text { Before } \\
\text { subject } \\
\text { taught }\end{array}$ & $\begin{array}{c}\text { After } \\
\text { subject } \\
\text { taught }\end{array}$ \\
\hline \multicolumn{11}{|c|}{ Closed system } \\
\hline \multirow{2}{*}{ Correct } & \multirow{2}{*}{$46 \%$} & \multirow{2}{*}{$79 \%$} & \multirow{2}{*}{$36 \%$} & \multirow{2}{*}{$81 \%$} & \multirow{2}{*}{$57 \%$} & \multirow{2}{*}{$79 \%$} & \multirow{2}{*}{$39 \%$} & \multirow{2}{*}{$69 \%$} & A. $75 \%$ & $89 \%$ \\
\hline & & & & & & & & & B. $76 \%$ & $87 \%$ \\
\hline \multirow{2}{*}{ Incorrect } & \multirow{2}{*}{$54 \%$} & \multirow{2}{*}{$21 \%$} & \multirow{2}{*}{$64 \%$} & \multirow{2}{*}{$19 \%$} & \multirow{2}{*}{$43 \%$} & \multirow{2}{*}{$21 \%$} & \multirow{2}{*}{$61 \%$} & \multirow{2}{*}{$31 \%$} & A. $25 \%$ & $11 \%$ \\
\hline & & & & & & & & & B. $24 \%$ & $13 \%$ \\
\hline \multicolumn{11}{|c|}{ Open system } \\
\hline Question no. & \multicolumn{2}{|c|}{6} & \multicolumn{2}{|c|}{7} & \multicolumn{2}{|c|}{8} & \multicolumn{2}{|c|}{9} & \multicolumn{2}{|c|}{10} \\
\hline Correct & $66 \%$ & $81 \%$ & $39 \%$ & $54 \%$ & $82 \%$ & $90 \%$ & $20 \%$ & $56 \%$ & A. $70 \%$ & $86 \%$ \\
\hline Incorrect & $34 \%$ & $19 \%$ & $61 \%$ & $46 \%$ & $18 \%$ & $10 \%$ & $80 \%$ & $44 \%$ & A. $30 \%$ & $14 \%$ \\
\hline
\end{tabular}

Table 3. Means and standard deviations of student conceptions in Arab sector of the conservation of mass during combustion in closed and open systems before and after the subject was taught, and the values of the t-test (N-195)

\begin{tabular}{|c|c|c|c|c|}
\hline Conceptions (correct/incorrect) & Before/After & Mean & SD & t-value \\
\hline \multicolumn{5}{|c|}{ Closed system } \\
\hline \multirow{2}{*}{ Correct } & Before & 54.84 & 16.60 & \multirow{2}{*}{$t=-5.109 * \star$} \\
\hline & After & 80.66 & 6.76 & \\
\hline \multirow{2}{*}{ Incorrect } & Before & 45.16 & 14.73 & \multirow{2}{*}{$\mathrm{t}=6.281^{\star *}$} \\
\hline & After & 19.34 & 7.56 & \\
\hline \multicolumn{5}{|c|}{ Open system } \\
\hline \multirow[t]{2}{*}{ Correct } & Before & 55.40 & 16.44 & $t=-3.901^{*}$ \\
\hline & After & 73.40 & 9.57 & \\
\hline \multirow[t]{2}{*}{ Incorrect } & Before & 44.60 & 14.73 & $t=4.102^{*}$ \\
\hline & After & 26.60 & 7.56 & \\
\hline
\end{tabular}

${ }^{*} p<.05, \quad{ }^{* *} p<.01$

As shown in Table 2, the percentage of misconceptions held by eighth grade students concerning the conservation of mass during combustion in a closed system was larger before the subject was taught than afterwards. The percentage of misconceptions held by eighth grade students concerning the conservation of mass during combustion in an open system was larger before the subject was taught than afterwards.

In order to determine the statistical significance of the effect of teaching on the number of misconceptions among students, a t-test was conducted on dependent samples. The findings are presented in Table 3.

As Table 3 shows, there is a significant difference between the means: The mean for misconceptions regarding the conservation of mass during combustion in a closed system before the subject was taught $(\mathrm{M}=45.16, \mathrm{SD}=14.73)$ was significantly higher than after the subject was taught $(M=19.34, S D=7.56)$. The findings point to a significant difference between means: The mean for misconceptions regarding the conservation of mass during combustion in an open system before the subject was taught $(M=44.60, S D=14.73)$ was significantly higher than after the subject was taught $(M=26.60, S D=7.56)$. There was a significant difference after the subject had been taught between means in a closed system $(M=80.66, S D=6.76)$, in contrast with an open system $(M=73.40, S D=16.44)$. Before the subject had been taught, the means were very similar.

\section{Findings for the Second Research Question}

After the questionnaires were returned, the results (answers) for questions 1-4 (closed system) and 6-9 (open system) were compared with the results to the respective questions in the questionnaire used by Dayan (2005). The students' responses to each question were classified as either correct or incorrect.

As Table 4 shows, the two sectors differed with respect to the percentage of students' correct answers regarding the subject of the conservation of mass during combustion in a closed system in questions 3 and 4 , whereas the difference in questions 1 and 2 was less significant. Furthermore, the percentages of correct answers after the subject had been taught were different in the two sectors: 81 percent of students in the Arab sector provided a correct judgment for question 2, in contrast with only 68 percent of the students in the Jewish sector. In the other questions, the differences between the sectors were not significant. Table 4 also shows that the two sectors differed with respect to the percentage of correct answers by students regarding the conservation of mass during combustion in an open system before the subject was taught, in all questions except for question 9, where no significant difference 
Table 4. Distribution of correct answers by students of the Arab versus the Jewish sector, for combustion in a closed system (questions 1-4) and an open system (questions 6-9) before and after the subject was taught

\begin{tabular}{|c|c|c|c|c|}
\hline \multirow[t]{2}{*}{ Question no. } & \multicolumn{2}{|c|}{ Arab sector $(N-195)$} & \multicolumn{2}{|c|}{ Jewish sector $(N-105)$} \\
\hline & Before & After & Before & After \\
\hline \multicolumn{5}{|c|}{ Closed system } \\
\hline 1 & $46 \%$ & $79 \%$ & $42 \%$ & $72 \%$ \\
\hline 2 & $36 \%$ & $81 \%$ & $28 \%$ & $68 \%$ \\
\hline 3 & $57 \%$ & $79 \%$ & $24 \%$ & $73 \%$ \\
\hline 4 & $39 \%$ & $69 \%$ & $22 \%$ & $39 \%$ \\
\hline \multicolumn{5}{|c|}{ Open system } \\
\hline 6 & $66 \%$ & $81 \%$ & $38 \%$ & $82 \%$ \\
\hline 7 & $39 \%$ & $54 \%$ & $53 \%$ & $73 \%$ \\
\hline 8 & $82 \%$ & $90 \%$ & $37 \%$ & $78 \%$ \\
\hline 9 & $20 \%$ & $56 \%$ & $18 \%$ & $74 \%$ \\
\hline
\end{tabular}

Table 5. Means and standard deviations for Arab and Jewish sector eighth grade students' conceptions regarding the conservation of mass during combustion in an open and a closed system, before and after the subject was taught, and the t-test values

\begin{tabular}{|c|c|c|c|c|c|c|}
\hline \multicolumn{2}{|c|}{ Conceptions - closed system } & \multicolumn{2}{|c|}{ Arab sector $(N-195)$} & \multicolumn{2}{|c|}{$\begin{array}{c}\text { Jewish sector } \\
(N-105)\end{array}$} & \multirow[t]{2}{*}{ t-value } \\
\hline & & Mean & SD & Mean & SD & \\
\hline \multirow{2}{*}{ Correct } & Before subject was taught & 44.50 & 16.60 & 29 & 9.50 & $\mathrm{t}=2.347^{*}$ \\
\hline & After subject was taught & 77 & 6.76 & 70.5 & 2.94 & $\mathrm{t}=0.778$ \\
\hline \multirow{2}{*}{ Incorrect } & Before subject was taught & 56.50 & 14.73 & 71 & 9.50 & $t=-3.599 * *$ \\
\hline & After subject was taught & 23 & 6.14 & 29.5 & 2.94 & $\mathrm{t}=-3.523^{* *}$ \\
\hline \multicolumn{7}{|c|}{ Conceptions - open system } \\
\hline \multirow{2}{*}{ Correct } & Before subject was taught & 51.75 & 14.0 & 36.50 & 15.15 & $t=1.016$ \\
\hline & After subject was taught & 70.25 & 6.57 & 76.75 & 4.11 & $t=-1.424$ \\
\hline \multirow{2}{*}{ Incorrect } & Before subject was taught & 48.25 & 16.30 & 63.50 & 15.15 & $t=-1.737$ \\
\hline & After subject was taught & 29.75 & 4.57 & 23.25 & 4.11 & $t=0.124$ \\
\hline
\end{tabular}

${ }^{*} p<.05,{ }^{* *} p<.01$

was observed. For question 6, 66 percent of students in the Arab sector gave a correct answer, compared with 38 percent in the Jewish sector, whereas for question 7, 39 percent of the students in the Arab sector gave a correct answer, compared with 53 percent in the Jewish sector. The largest difference was in question 8, where 82 percent of the students in the Arab sector gave a correct answer, compared with only 37 percent of the students in the Jewish sector. After the subject was taught, the percentage of correct answers differed in the two sectors for all questions except question 6. Seventy-three percent of the students in the Jewish sector gave a correct answer for question 7, compared with 54 percent of students in the Arab sector. For question 8, 90 percent of the students in the Arab sector gave a correct answer, compared with 78 percent in the Jewish sector. Again, for question 9, in the Jewish sector 74 percent of the students gave a correct answer, compared with 56 percent in the Arab sector.

In order to determine whether the differences between students' conceptions in the two sectors were statistically significant, we conducted a t-test on the independent samples. The findings are presented in Table 5.

As Table 5 shows, a significant difference exists between the percentages of correct answers given by Arab and Jewish eighth grade students with respect to the conservation of mass during combustion in a closed system, before the subject was taught $(t=2.347, p<.05)$. No significant difference between the two sectors was found after the subject had been taught.

With respect to the conservation of mass during combustion in an open system, the differences between students of the two sectors were not significant, both before and after the subject was taught.

\section{DISCUSSION}

The findings indicate that eighth grade students adhere to a number of misconceptions concerning the conservation of mass in both open and closed systems, before and after the subject is taught. As expected, the percentage of misconceptions before the subject was taught was greater than after it was taught.

Students' explanations were occasionally based on visual considerations, which subsequently changed to logical arguments based on the scientific explanation of combustion as oxidation, accompanied by the emission of heat and light (Melamed, 2000). This was concluded, based on experiments performed by the students in the classroom, in which they measured masses before and after combustion in an open and a closed system. Visual 
considerations were evident in the answers to question 1 , such as "the volume will be smaller, and so will the mass" and to question 2 , such as "the mass is not equal because during combustion the mass decreases". A much smaller percentage of students had an erroneous explanation after the subject had been taught than before. A possible explanation for retention of the erroneous explanation is that it involved acquired concepts that were not easy to replace (Nussbaum \& Yehieli, 1995), or that the error is intuitive rather than due to lack of knowledge, that is, it reflects a student's opinion that was formed without reliance on either previous or new knowledge (Melamed, 2000). Students also had explanations based on a visual consideration for question 7 , "the mass is smaller than before the candle was lit, because it shrinks and becomes smaller", and for question 9, "because the paper was solid and then became ash"; these are erroneous judgments based on general misconceptions (Nussbaum \& Yehieli, 1995, p. 15), which are quite tenacious: students hold on to such misconceptions because they believe that they are reasonable, since they are based on their own experiences, and therefore, they find it difficult to replace them (Yaakov, 1988).

Among the answers to question 1 concerning a closed system, students noted that part of the matter evaporated and explained that when this happened, the matter disappeared. This is also consistent with the findings of Ochsendorf and Pyke (2004), and Barker and Miller (1999), where 37 percent of the students replied that there was a change in mass.

In their answers to question 3, more students explained that "the matter turned into gas" before the subject was taught than afterwards. Similar responses were noted by Furio-Mas, Perez, and Harris (1987), who found that students believed that "when gas is released the mass becomes smaller". In answering question 7, concerning an open system, students argued that the mass "decreased, because the wax became liquefied". Before the subject was taught, some of the students said that the mass was "equal, because the matter only changed its state".

Many researchers who studied this topic concluded that students continue to adhere to misconceptions even after the subject was taught (Ayas \& Ozmen, 2003; Gabel, Makinster, Monaghan, \& Stockton, 2007; Haider, 1996; Ochsendorf \& Pyke, 2004). Similarly, to previous studies (Driver, 1985), an analysis of the findings revealed that some students use non-existent concepts in order to explain their replies to questions regarding chemical reactions.

Comparison of open and closed systems: A comparative analysis of students' answers to questions 1-5 on closed systems and questions 6-10 on open systems showed that eighth grade students did not distinguish between mass conservation in the case of chemical reactions through combustion in the two system types.

In their answers to questions 1 and 3, regarding combustion in a closed system, a large percentage of students used erroneous judgments before (and some even after) the subject had been taught, and gave the incorrect answer that "oxygen atoms were added from the air, and therefore, the mass increased", an argument that ignores the fact that the system is closed. They did not realize that the oxygen used for combustion was already part of the system and that it did not enter from the outside.

In answering question 3, students said that "the mass decreases because during combustion there were oxygen atoms, which subsequently disappeared". This conception is in line with similar results obtained by Ayas and Ozmen (2003), who found that students adhere to the misconception that mass always decreases in chemical reactions in a closed system.

In answering question 7 regarding a candle burning in an open system, students erroneously replied that the "candle's mass after it burned was equal to its mass before", and explained that this occurred because "no matter was added and none was taken away". Similarly, Ochsendorf and Pyke (2004) found that students hold on to misconceptions about chemical reactions ("if the product's matter is only transformed"). They realize that a chemical reaction has taken place but do not distinguish between an open and a closed system.

In their answers to question 9, before the subject was taught, some students said that "no oxygen atoms were added". Even after it was taught, some students continued to adhere to misconceptions owing to their not having made a distinction between open and closed systems, in addition to confusion about the nature of the chemical reactions that take place during combustion. The answers to question 10 confirm this: some of the students said "that gases are produced that are released into the air" during the burning of a strip of magnesium.

In their answers the students used physical changes that take place during combustion. When learning the subject, apparently they are not taught the difference between physical and chemical changes in combustion, arguing that the burned matter merely changed form. The students continued to adhere to this misconception even after the subject had been taught, in line with the findings of Ayas and Ozmen (2003), based on chemical changes during combustion in a closed and an open system.

Among the students who took part in the study, certain serious misconceptions were found concerning vital concepts in chemistry that should have been corrected before high school. In a study of high-school students who had just finished a lesson on chemical changes, the students were exposed to the topic of chemical reactions during oxygen reduction and were asked to explain what had happened. The study showed that the students could not distinguish between physical and chemical changes and were unable to explain specific processes (such as the 
release of gas). Some, in their replies, referred to everyday experiences. The study's results show the need for fundamental changes in how chemistry is taught in school (Hesse, 2006).

To conclude, the percentage of wrong answers seems to show that students had more difficulty with questions about open than about closed systems after the subject had been taught (see Table 6), whereas the differences in students' answers to questions concerning the two kinds of systems before the subject had been taught were not very large.

The Arab versus the Jewish sector: First of all, it should be pointed out that in the Arab sector the topic at hand (conservation and the change in mass during combustion) was taught for six lessons, whereas it was taught for nine lessons in the Jewish sector, due to more discussions and experiments in the latter. However, the curriculum is identical for all middle schools in the country and is certified by the Israel Ministry of Education (Levy Nahum et al., 2010).

Questions 1-4 deal with the conservation of mass for different states of matter in a closed system. The distribution of students' answers for questions 1 and 2 were nearly identical in the two sectors, before and after the subject had been taught. It is important to note that the first two questions do not require very sophisticated thinking, since they deal with the combustion of solids, something with which students are generally familiar from their everyday lives. Therefore, the distributions of answers for students in both sectors were almost identical. The same is true of the distribution of answers to questions 3 and 4, which also deal with materials with which the students are familiar. Question 3 deals with the combustion of a liquid, which was already taught in class in the present study, and also in the Jewish sector; the distribution of answers highlights this. In question 4 the subject is again "solids", but this time students know the result, having learned about the law of the conservation of matter in a closed system. However, the distribution of the answers to questions 3 and 4 before the subject had been taught was different in the two sectors, because the students came from different backgrounds, different schools, and perhaps also experienced different teaching methods in primary school. For this reason, students possess different conceptions concerning the law of the conservation of mass (Boujaoude, 1991).

A perusal of the findings with respect to questions 6-9 regarding the law of the conservation of mass in a solid in an open system shows the distribution of answers for the two sectors.

As for question 6, the distribution of answers after the subject had been taught was nearly identical in both sectors. In the experiment described, in these questions the students referred to the addition of oxygen atoms, as reflected by the comment "a white substance was created in the air", clearly indicating that the students treated the system as closed. However, from the answers to question 7, we see that in the Arab sector a larger percentage of students maintained their misconceptions after the subject had been taught than was the case in the Jewish sector. Question 7 is not easy, since it requires thinking about the chemical process that takes place when a candle burns and the production of new materials, some of which are in a gaseous state and are released into the air. The arguments provided by the students for this question were based on visual considerations, that is, on the physical changes, rather than on the gases released into the air, and therefore, these students did not take the mass of these gases into consideration. Question 7 is similar to the question posed by Ochsendor and Pyke (2004), who asked about the mass of a piece of wood that burned completely and turned into ash in an open system; some of the students maintained that the mass decreased.

The distribution of students' correct answers to question 8 in the Arab sector before and after the subject was taught shows that even before the subject was taught, many students gave correct answers and this situation improved even more after it was taught. The question dealt with the combustion of iron oxide in air; the words "oxide" and "air" both appeared in the question, thus helping students realize that oxygen atoms were added and therefore, the mass increased. This was relatively easy for the students because they had already encountered this issue when they were taught about the combustion of a piece of zinc. In the Jewish sector, on the other hand, the percentage of correct answers before the subject was taught was quite low, but improved considerably after it had been taught.

In their answers to question 9 many of the students in the Arab sector, but considerably fewer in the Jewish sector, retained misconceptions after the subject had been taught. Question 9 is quite similar to question 7, but in question 9 the correct answer is already included in the question itself, and students were only required to explain it. The distribution of students' answers in both sectors after the subject had been taught was similar for both questions. The analysis of question 9 is identical to that of question 7, namely, that it requires students to think carefully about why the mass of the paper decreased after combustion. To do this, it is necessary to consider the chemical process that took place in an open system, as well as the fact that new materials are formed, some of which are gases that are released into the air. These results are in line with previous studies which deals with different sectors and cultures and their impact on coping in the classroom and in the school received much attention. A comparison between the Jewish and the Arab populations in Israel is interesting because it contains many factors that can be addressed, including cultural-ethnic factors, the influence of religion, intellectual ability, academic achievements, and more. In Israel, various studies have been carried out in the teaching of sciences that examined 
cultural-sector differences between Arabs and Jews (Birenbaum et al., 2007; Dkeidek et al., 2012; Markic et al., 2016; Tamir \& Caridin, 1985). Most of the findings in these studies indicated many differences between the two sectors.

Thus, with respect to the second research question, the study's findings show that conceptual differences exist between eighth graders in the two sectors. The differences were particularly significant in the answers to questions 7 and 9. These questions dealt with open systems, which required a higher level of thinking; in their answers the students in the Arab sector had more misconceptions than their peers in the Jewish sector had. On the other hand, in questions 1-3, which dealt with closed systems, students in the Arab sectors had fewer misconceptions than did the students in the Jewish sector. In question 4 the results for both sectors were identical.

\section{CONCLUSIONS AND RECOMMENDATIONS}

It is important to note that students' erroneous answers were mostly based on visual considerations due to changes in the states of matter, and due to students' inability to distinguish between chemical reactions during combustion that took place in closed versus open systems, and in general, the effect on the mass of a system's being closed or open. Overall, the percentage of misconceptions before the subject had been taught was greater than after it had been taught in both sectors and for all questions, an unsurprising result. The present study revealed some misconceptions that proved difficult to change, due to interaction with the environment (Yaakov, 1988). Another unambiguous conclusion is that the percentage of misconceptions about the conservation of mass in an open system is higher than in a closed system among students of both sectors. However, the misconceptions in the two sectors are not always the same, especially with respect to questions that require high-level thinking, conceptions having to do with closed systems, as well as combustion in an open system with the addition of oxygen atoms.

The limitations of this study include the fact that the students studied are from a specific area in the Arab sector in Israel. Another limitation is that the results obtained in the present study are only in the Arab sector and were compared to results of a previous study conducted in the Jewish sector (Dayan, 2005) not at the same time of this study. In light of the study's results, it is recommended that eighth grade students' misconceptions regarding combustion be revealed before the subject is taught. Explanations should be accompanied by experiments that show the effect of oxygen on matter, and the subject should be addressed not only from a visual perspective-it should also include a discussion of the relevant chemical reaction. This will provide students with the correct meaning of the concept. It is important to discuss the possible source of the misconceptions, to determine whether these misconceptions may lead to others in other domains, and to discover ways for solving and preventing this problem (Hirsch \& Amir, 2001).

This study has some limitations. The first one is that the sample of the study is not statistical; it depended on accessible classes in the Arab and the Jewish sectors by the teachers' agreement and the principal's permision to take part in the study. Besides, the study conclusions are suitable to the population that was examined, and it is necessary to be careful to generalize them to the whole Arab and Jewish sectors. Probably, if another study is conducted in different geographical areas and includes other communities, it will add different conclusions.

Finally, to clarify the complex picture of misconceptions among students, further research is needed. It is possible that conducting in-depth interviews will help to create a deeper understanding of various factors, sector and culture dependent that shapes the entire range of variables that influence the creation of misconceptions.

\section{REFERENCES}

Abdu, B. (1999). Conceptual Concepts in an Arabic-speaking Population in Israel (Unpublished Doctoral dissertation), Hebrew University of Jerusalem, Israel.

Andersson, B. (1984). Chemical reactions. EKNA Report No: 12, University of Göteborg, Göteborg.

Ayas, A., \& Ozmen, H. (2003). Student's difficulties in understanding of the conservation of matter in open and closed-system chemical reactions. Chemistry Education Research and Practice, 4, 279-290. https:/ / doi.org/10.1039/B3RP90017G

Barker, V., \& Millar, R. (1999). Students reasoning about chemical reactions: What changes occur during a context based post-16 chemistry course? International Journal of Science Education, 21, 645-665. https://doi.org/10.1080/095006999290499

Birenbaum, M., Nasser, F., \& Tatsuoka, C. (2007). Effects of gender and ethnicity on fourth graders' knowledge states in mathematics. International Journal of Mathematical Education in Science and Technology, 38, 301-319. https:/ / doi.org/10.1080/00207390601116052

Boujaoude, S. (1991). A study of the nature of student's understanding about the concept of burning. Journal of $\begin{array}{lllll}\text { Research } & \text { Science } & \text { Teaching, } & \text { 689-704. }\end{array}$ https://doi.org/10.1002/tea.3660280806 
Cañada, F., González-Gómez, D., Airado-Rodríguez, D., Niño, L., \& Acedo, M. (2017). Change in elementary school students' misconceptions on material systems after a theoretical-practical instruction. International Electronic Journal of Elementary Education, 9(3), 499-510.

Dayan, A. (2005). Conceptions of Middle School Students on Conservation of Mass during Combustion (Master's Thesis). Retrieved from https://www.tau.ac.il/research/archive.

Dkeidek, I., Mamlok-Naaman, R., \& Hofstein, A. (2012). Assessment of the laboratory learning environment in an inquiry-oriented chemistry laboratory in Arab and Jewish high schools in Israel. Learning Environments Research, 15(2), 141-169. https:/ / doi.org/10.1007/s10984-012-9109-3

Driver, R., Guesne, E., \& Tiberghien, A. (1985). Children's ideas in science. Philadelphia, PA: Open University Press.

Eilks, I., Moellering, J., \& Valandies, N. (2007). Seventh-grade student's understanding of chemical reactions reflections from an action research interview study. Eurasia Journal of Mathematics, 3(4), 271-286. https:/ / doi.org/10.12973/ ejmste/75408

Fisher, K. (1985). A misconception in biology: Amino acids and translation. Journal of Biology Education, $22,53-62$. https:/ / doi.org/10.1002/ tea.3660220105

Furio-Mas, C. J., Perez, J. H., \& Harris, H. H. (1987). Parallels between adolescents' conceptions of gases and the history of chemistry. Journal of Chemical Education, 64(7), 616.

Gabel, D., Makinster, J., Monaghan, D., \& Stockton, J. (2007). Changing children's conceptions of burning. School Science and Mathematics, 101, 439-451. https:/ / doi.org/10.1111/j.1949-8594.2001.tb17879.x

Gillespie, R. J. (1997). The great ideas of chemistry. Journal of Chemical Education, 74(7), 862-864.

Haider, A. (1997). Prospective chemistry teacher's conceptions of the conservation of matter and related concepts. Journal of Research in Science Teaching, 34, 181-197.

Hesse, J. (2006). Student's conceptions of chemical change. Journal of Research in Science Teaching, 29, 277-299. https://doi.org/10.1002/tea.3660290307

Hirsch, A., \& Amir, R. (2010). Tipool memokad b'tfisoot shgoiut [Focused Treatment of Misconceptions]. PetachTikva: Center for Science Teaching, 1-6 (in Hebrew).

Leigh K., \& Mehmet, A. (2012). What do middle and high school students know about the particulate nature of matter after instruction. School Science and Mathematics, 112, 59-65. https://doi.org/10.1111/j.1949-8594.2011.00120.x

Levy Nahum, T., Moial, A., Somekh, D., \& Koshinsky, N. (2010). Elements, Characteristics and Processes (experimental edition), Rehovot: Weitzmann Institute and the Ministry of Education.

Markic S., Eilks I., Mamlok-Naaman, R., Hugerat, M., Kortam, N., Dkeidek, I. \& Hofstein, A. (2016). One country, two cultures - a multi-perspective view on Israeli chemistry teachers' beliefs about teaching and learning.

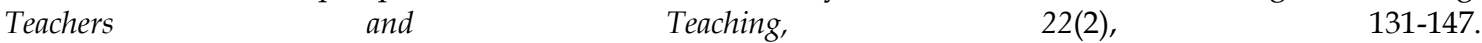
https:/ / doi.org/10.1080/13540602.2015.1055423

Melamed, E. (2000). Intuition in changing worlds. Aleh, 26, 9-12.

Mendelowits, R. (1996). Scientific thinking and research skills. He-Alon le-Morei ha-Biologiya, 147(c), 1-9.

Nakhleh, M. (1992). Why some students don't learn Chemistry: Chemical misconceptions. Journal of Chemical Education, 69(3), 191-196.

Nussbaum, Y., \& Yehieli, T. (1995). Misconceptions and Conceptual Change in Science Teaching. Tel-Aviv, MOFET Institute.

Ochsendorf, R., \& Pyke, C. (2004). Conservation of Matter Assessment Manual. Rockville, MD: Montgomery Country Public Schools, George Washington University.

Piaget, J., \& Inhelder, B. (1974). The child's construction of quantities. London: Routledge.

Prieto, T., Watson, R., \& Dillon, J. (1992). Pupils' understanding of combustion. Research in Science Education, 22, 331-340.

Pundak, D., Rosner, S., \& Maharshak, A. (2005). [Naïve Conceptions and Active Learning]. Orte Braude Academic College of Engineering, 4, 13-17.

Sanz, A. (2006). Student's ideas on conservation of matter: effects of expertise and context. Science Education, 79, 7793. https:// doi.org/10.1002/sce.3730790106

Stavy, R. (1990a). Children's conception of changes in the state of matter: From liquid (or solid) to gas. Journal of Research in Science Teaching, 27, 247-266. https:/ / doi.org/10.1002/tea.3660270308

Stavy, R. (1990b). Children's ideas about matter. School Science and Mathematics, 91, $240-244$. https:/ / doi.org/10.1111/j.1949-8594.1991.tb12090.x 
Stavy, R. (1990c). Pupils' problems in understanding conservation of mass. International Journal of Science Education, 12(5), 501-512.

Tamir, P. \& Caridin, H. (1993). Characteristics of the learning environment in biology and chemistry classes as perceived by Jewish and Arab high school students in Israel. Research in Science and Technological Education, $11,5-14$.

Watson, R., \& Prieto, T. (1994). Secondary science in England and Spain. Education in Chemistry, 31(2), 41-41.

Watson, R., Prieto, T., \& Dillon, J. (1995). The effect of practical work on students' understanding of combustion. Journal of Research in Science Teaching, 387-502. https:// doi.org/10.1002/tea.3660320506

Yaakov, A. (1988). Hesberim l'atfesoot motaut shil madaim hametsuyeem b'hesberim [Sources for misconceptions of scientific explanations found in the explanations]. He-Alon le-Morei ha-Biologiya, b, 1-4.

\section{APPENDIX 1}

\section{Knowledge Questionnaire}

Dear student

Please answer the following questions;

1. Choose the right sentence to the best of your understanding

2. Explain as needed.

\section{Questions:}

1. A piece of phosphorus with a little water were kept in a closed bottle. The mass of the bottle and its contents was 400 grams. Sunrays passing through the lens focused on the phosphorus and caused it to burn. The slowly formed white smoke dissolved in the water found in the bottle. The mass of the bottle after burning the piece of phosphorus:
A. Equals 400 grams.
B. more than 400 grams.
C. less than 400 grams.
Explain:

2. An astronaut was smoking a cigarette in a perfectly sealed spacecraft. Therefore, the mass of the space ship (with everything in it) after smoking will be:
A. Bigger
B. smaller
C. Equal to the mass before smoking.
Explain.

3. Measure liquid alcohol mass in a closed container. Then, burn the alcohol in the closed container and measure its mass again.

Does the mass of the closed vessel after the burning of alcohol remain equal or does it change? Please explain your answer: 
4. Measure the mass of a piece of paper while the vessel is closed. Then, burn the piece of paper in the closed tool and measure its mass again. The mass of the sealed tool with the sheet of paper is:
A. Bigger than the mass of the vessel with the page before its burning.
B. Smaller than the mass of the vessel with the sheet before its burning.
C. Equal to the mass of the vessel with the page before its burning.

5. Measure 5 grams of steel were measured; then burned and the mass was measured again. It was six-gram.

\section{A. What led to the rise of mass?}

\section{B. What happens in your opinion if the experiment is done with a closed tool?}

6. As a result of burning magnesium in the air, white matter is obtained.

What can we say about the mass of white matter?
A. Less than the mass of magnesium, because magnesium became lighter when heated.
B. Less than the mass of magnesium, because the magnesium disintegrated.
C. Equal to the mass of magnesium, because oxygen atoms from the air were added to the atoms of magnesium.

7. Place a candle in the air on the scales and read its mass. Then, light the candle, and read its mass again. The mass of the candle, after it was burned, will be:
A. Smaller than before it was burned.
B. Bigger than before it was burned.
C. Equal to the mass before it was burned.
Explain:

8. When iron wool is burned in the air, we get gray iron oxide. What can we say about the mass of gray matter compared to the mass of iron wool?
A. Bigger, because the material has spread.
B. Bigger, because the material was merged with oxygen from the air.
C. Smaller, because the volume is small.
D. Smaller, because the iron disintegrated.

9. The mass of a sheet of paper was measured and burned in the air. Then, the ash mass of the burned paper was measured. It turned out that it had become smaller.

Explain why the ash mass of the burned page became smaller after burning the paper in the open air? Explain: 
10. The figure in front of you; illustrates the balance of the scales, with one stripe of magnesium on top of it before burning it.

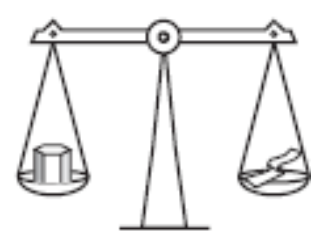

A. Choose the figure that illustrates the stripe of magnesium after burning (Arrow refers to magnesium oxide).

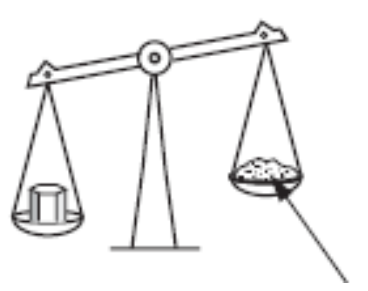

\section{1}

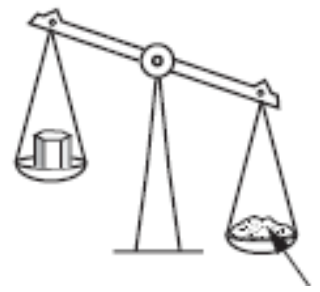

2

B. What led to the change in magnesium mass after its combustion?

http://www.ejmste.com 